\title{
New multi-stage DC-DC converters for grid-connected photovoltaic systems
}

\begin{abstract}
Renewable energy is high on international and national agendas. Currently, grid-connected photovoltaic (PV) systems are a popular technology to convert solar energy into electricity. Existing PV panels have a relatively low and varying output voltage so that the inverter installed between the PVs and the grid should have high step-up and versatile control capabilities. In addition, the output currents of PV systems are rich in harmonics which affect the power quality of the grid. In this paper, a new step-up multilevel inverter with an improved hysteresis control scheme is proposed for integrating PVs into a single-phase power grid. The proposed circuitry and control method is experimentally validated by testing on a $600 \mathrm{~W}$ prototype converter. The developed technology has significant economic implications and could be applied to many distributed generation (DG) systems, especially for the developing countries which have a large number of small PVs connected to their single-phase distribution network.
\end{abstract}

Index Terms-hysteresis control, multilevel inverter, photovoltaic, step-up DC-DC, total harmonic distortion.

\section{INTRODUCTION}

W ITH increasing concerns over global warming and the depletion of fossil fuels, substantial investment and effort has been directed towards developing renewable energy technologies. The clean electricity generation based on photovoltaic (PV) technology is one of the prevalent solutions. In the literature, there are three types of grid-connected PV system configurations reported: the central type, string type and modularized type [1]-[3], as depicted in Fig. 1. The first systems connect PV modules in series and then in parallel so as to increase their direct current $(\mathrm{dc})$ bus voltage and power. They generally have high-voltage high-current output and are suited for large-scale $(>5 \mathrm{~kW})$ three-phase systems. But they suffer from high power losses and high current harmonics, the shadow effect and the PV module mismatch [4]-[7]. The second require an individual maximum power point tracking (MPPT) for each string. They have high-voltage low-current output, and they are efficient and suitable for medium-scale $(2-5 \mathrm{~kW})$ single-phase systems. In contrast, the last type requires an individual power converter and MPPT for each PV module. As a result, these systems typically have low-voltage low-current output and require high installation costs. They may be suited well for small-scale $(<2 \mathrm{~kW})$ single-phase systems. In practice, the second configuration is the dominant type in PV applications and is therefore the focus of this paper.
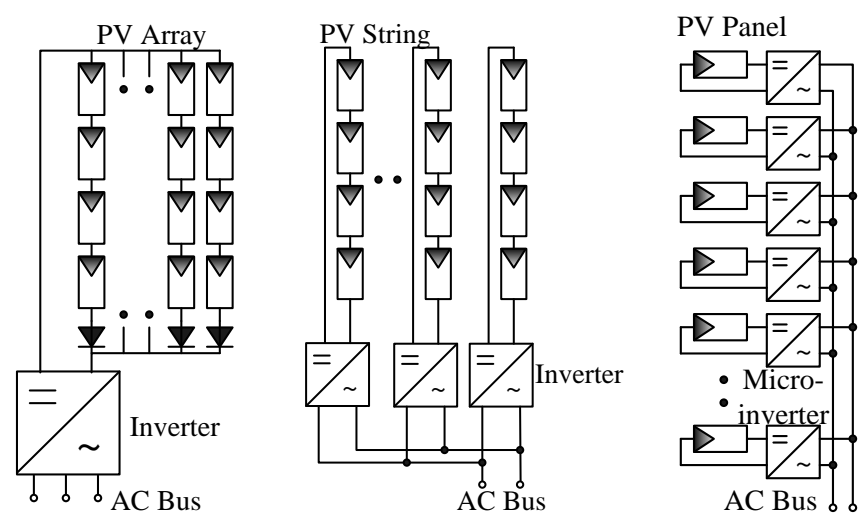

(a) The central type. (b) The string type. (c) The modularized type.

Fig. 1. Three types of PV system configurations.

In theory, the output voltage of one PV string is very low and varies over a wide range despite the use of MPPT. This requires the front-end dc-dc converter to be equipped with a step-up 
capability for grid connection [8]-[18] at the expense of power quality. On the other hand, the multilevel converter technology is advantageous to incorporate PVs into the power grid while achieving good output waveforms, reduced filter sizes and reduced electromagnetic interference (EMI) [19]-[26]. However, these converters are complex, costly, and low in voltage amplification. Therefore, it is desired to develop a combined high step-up and multilevel inverter with a minimal number of switching devices for grid-connected PV systems.

When connected to a power network, the PV systems must meet stringent power quality requirements set by the utility grid including low total harmonic distortion (THD) and fast dynamic response. In this regard, hysteresis current control is often chosen owing to its simplicity, robustness and good large-signal response. Nevertheless, the switching frequency of the converter varies with the bus voltage, filter inductance and bandwidth [27]-[29]. In the literature, the variable-hysteresis-band current control technique [27][30] and digital hysteresis modulation technique [31] are reported in use. They require multiple samples within a switching period and are thus complicated and computationally costly. Moreover, these hysteresis control methods are hardly used for asymmetric multilevel converters [32][33] which is the case for this study.

\section{Proposed Multilevel InVerter}

This paper proposes a new asymmetry multilevel inverter with improved hysteresis control scheme. As shown in Fig. 2, the inverter consists of a high step-up dc-dc converter, a three-level dc-dc converter and a line frequency commutated bridge.

\section{A. The High Step-up DC-DC Converter}

The equivalent circuit of the proposed converter is shown in Fig. 3. In the figure, $S_{0}$ is the main switch, $D_{0}$ and $D_{2}$ are the regenerative diodes, $D_{1}$ is the rectifier diode, $C_{1}$ and $C_{2}$ are the output filter capacitors, $C_{S}$ is the bootstrap capacitor, $U_{\text {in }}$ and $U_{d c}$ are the input and output voltages, and $R$ is the load. A coupled inductor $L_{C}$ with primary and secondary turns of $N_{p}$ and $N_{s}$ is also used to increase voltage gain. It is equivalent to an ideal transformer whose primary winding connected in parallel with a magnetizing inductor $L_{m}$ and then in series with a leakage inductance $L_{p}$.

The converter operates on two modes: continuous and discontinuous conduction, depending on the load.

\section{(1) Continuous conduction mode}

Voltage and current waveforms of the high step-up dc-dc converter in continuous conduction mode (CCM) are presented in Fig. 4(a) and four stages and current flow paths are illustrated in Fig. 4(b-e) for one full period and explained in detail as follows.

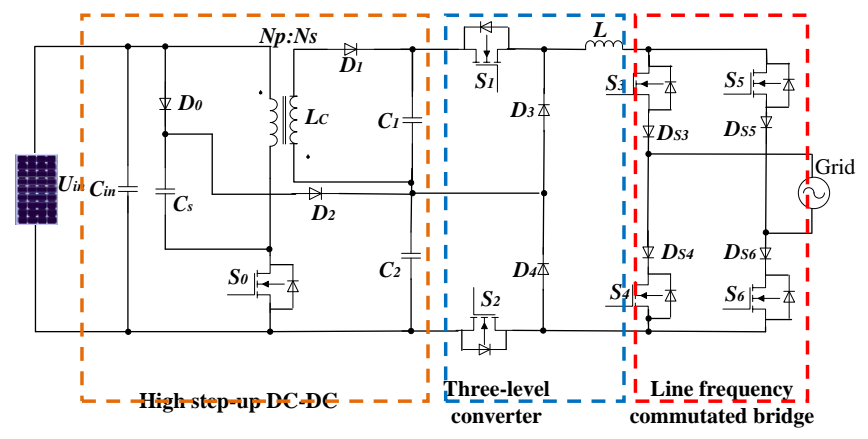

Fig. 2. Proposed high step-up multilevel inverter.

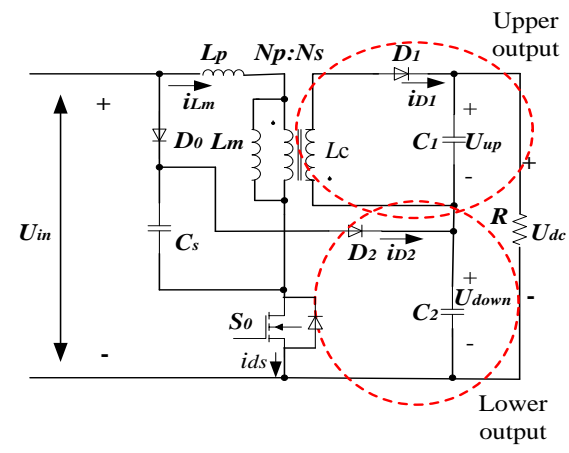

Fig. 3 Equivalent circuit of the high step-up dc-dc converter.

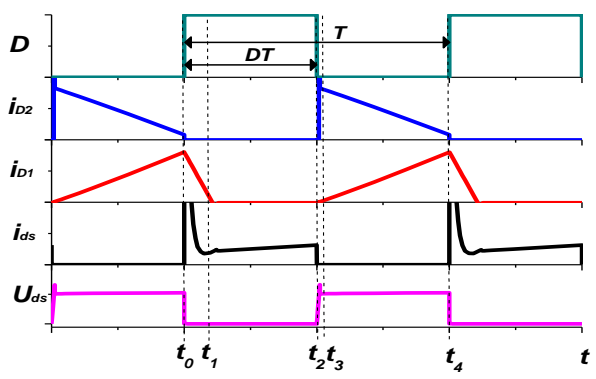

(a) Waveforms of the main devices under the CCM ( $T$ is the period and $D$ is the duty ratio).

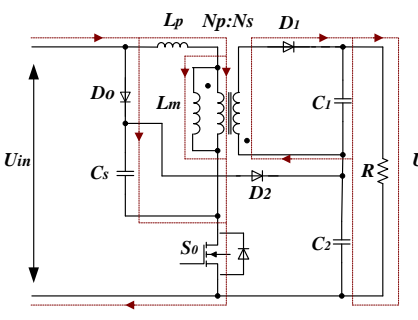

(b) Stage 1

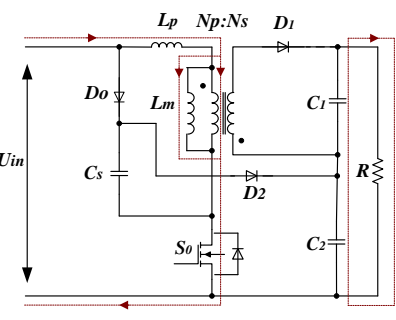

(c) Stage 2 


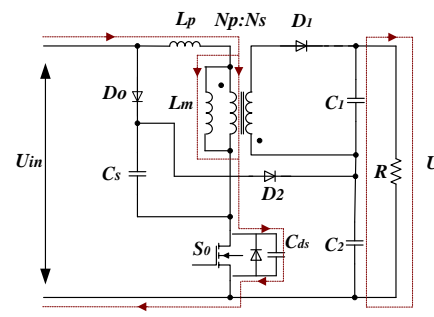

(d) Stage 3

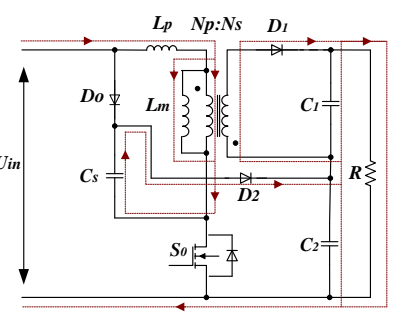

(e) Stage 4
Fig. 4. Operation of the CCM during a period.

- Stage $1\left(t_{0}-t_{1}\right): S_{0}$ is turned on and $D_{0}$ becomes forward biased. The current $i_{L m}$ increases and $i_{D l}$ decays quickly since the magnetizing inductance is energized from the input voltage source. Similarly, $C_{s}$ is charged by the source through $D_{0}$.

- Stage $2\left(t_{1}-t_{2}\right): S_{0}$ stays on. $D_{l}$ is reverse biased. The energy from the source is stored in $L_{m}, L_{p}$ and $C_{S}$. $C_{1}$ and $C_{2}$ are discharged through the load.

- Stage $3\left(t_{2}-t_{3}\right)$ : at the time $t_{2}, S_{0}$ is turned off. The stored energy starts to charge the parasitic capacitor $C_{d s}$ of $S_{0}$.

- Stage $4\left(t_{3}-t_{4}\right): S_{0}$ stays off. $D_{1}$ and $D_{2}$ conduct and $D_{0}$ is reverse biased. $C_{l}$ is charged through the secondary-side winding of $L_{C}$ while $C_{2}$ is charged through $C s$ and $L_{C}$.

When $S_{0}$ conducts, the input voltage imposes across $C s$ and the magnetizing current increases by:

$$
\Delta i_{L m(0 \sim D T)}=\frac{U_{i n}}{L_{m}+L_{p}} D T
$$

When $S_{0}$ is turned off, $C_{2}$ is charged by the input source via $C_{S}$ and $L_{C}$. The loop voltage equation is given by,

$$
U_{\text {in }}+U_{L_{m}}+U_{C_{S}(D T \sim T)}=U_{\text {down }}
$$

where $U_{L_{m}}$ is the primary side voltage of $L_{C}, U_{C_{s}(D T \sim T)}$ is the voltage across $C_{S}$, and $U_{\text {down }}$ is the voltage across $C_{2}$.

The voltage ripple can be calculated by:

$$
\Delta U_{C_{s}(D T \sim T)}=\frac{1}{C_{s}} \int_{D T}^{T} i_{D 2} d t \approx \frac{(1-D)}{C_{s} f} I_{D 2}
$$

where $I_{D 2}$ is the average current flowing through $D_{2}$, and $f$ is the switching frequency of $S_{0}$.

The current fluctuation in the primary side of $L_{C}$ is

$$
\Delta i_{L_{m}(D T \sim T)}=\frac{U_{d o w n}-U_{C_{s}(D T \sim T)}-U_{i n}}{L_{m}+L_{p}}(1-D) T
$$

Over one switching cycle, the net current change is zero in the inductor. Therefore,

$$
\frac{U_{\text {in }}}{L_{m}+L_{p}} D T=\frac{U_{d o w n}-U_{C_{s}(D T \sim T)}-U_{\text {in }}}{L_{m}+L_{p}}(1-D) T
$$

The step-up ratio can be computed from the sum of upperand lower-output voltages divided by the input voltage:

$$
G=\frac{U_{d c}}{U_{\text {in }}}=\frac{U_{u p}+U_{\text {down }}}{U_{\text {in }}} \approx \frac{2-D+\frac{N_{s}}{N_{p}} D}{1-D}
$$

The voltage stress of $S_{0}$ can be expressed as:

$$
U_{d s}=U_{\text {down }}-U_{\text {in }}+U_{\text {leak }}
$$

where $U_{\text {leak }}$ is the leakage voltage.

\section{(2) Discontinuous conduction mode}

When $S_{0}$ is turned off, the upper output is in the CCM whilst the lower output is in the discontinuous conduction mode (DCM). Fig. 5(a) and (b) show the voltage and current waveforms, and the current flow paths in the converter, respectively.

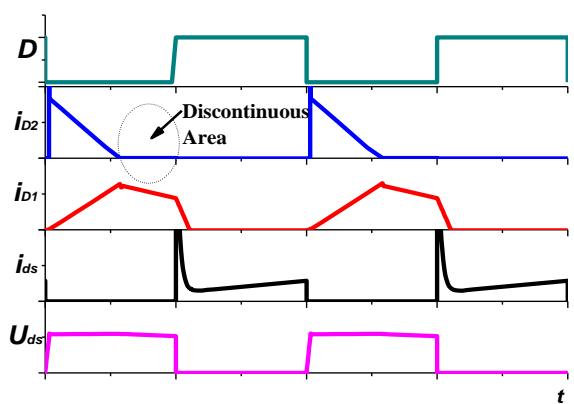

(a) Waveforms of the main devices under the DCM.

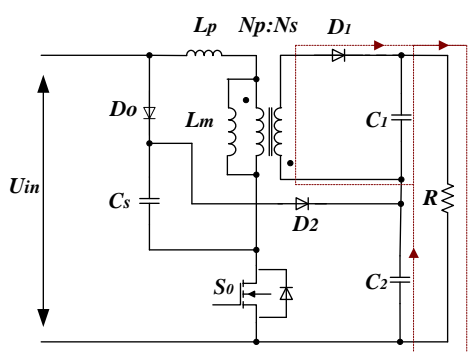

(b) Current flow paths under the DCM.

Fig. 5. Operation of the DCM during a period.

The DCM coefficient $\zeta$ can be found by,

$$
\zeta=\frac{D_{i D 2} T}{(1-D) T}
$$

where $D_{i D 2} T$ represents the conduction time for $D_{2}$.

In order to establish the relationship between the lower-output voltage and input voltage in the DCM, Eq. 9 can be derived following the volt-second balance.

$$
\int_{0}^{D T} U_{i n} d t=\int_{D T}^{\left(D+D_{i D 2}\right) T}\left(U_{d o w n}-U_{C_{s}\left(D T \sim D_{i D 2} T\right)}-U_{i n}\right) d t
$$

where $V_{C S(D T \sim D i D 2 T)}$ is the bootstrap capacitor voltage. 
The lower-output voltage gain for steady-state operation under the DCM can be derived from Eqs 1, 8 and 9,

$$
\frac{U_{\text {down }}}{U_{\text {in }}}=2-\frac{D}{\zeta(1-D)}
$$

Similarly, the output voltage gain under the DCM is given by,

$$
G=\frac{U_{d c}}{U_{\text {in }}}=2+\frac{\left(\frac{N_{s}}{N_{p}}-\frac{1}{\zeta}\right) D}{1-D}
$$

Because the off-state voltage of $S_{0}$ is clamped to $U_{\text {down }}-U_{\mathrm{C}_{\mathrm{S}}(\mathrm{DT} \sim \mathrm{T})}$, the proposed dc-dc converter has low voltage stress, rated voltage and conduction losses. More importantly, it can also generate double asymmetric output voltages ( $U_{\text {up }}$, $\left.U_{\text {down }}\right)$. The ratio of $U_{\text {down }} / U_{\text {up }}$ is determined by the turn's ratio of $L c$ (as in Fig. 6) and the related control strategy. The turns ratio of the coupled inductance can be designed to manipulate the proportion of $U_{u p}$ and $U_{\text {down }}$, which is the key to forming asymmetric multi-level voltages in the converter. For instance, when a low turns ratio is chosen, the duty ratio changing rate is low and so is the voltage gain suggested by Eqs 6 and 11. In this paper, the turns ratio of the coupled inductor is chosen to be 3 to strike a balance between the voltage gain and the $U_{u p} / U_{\text {down }}$ ratio by trial-and-error.

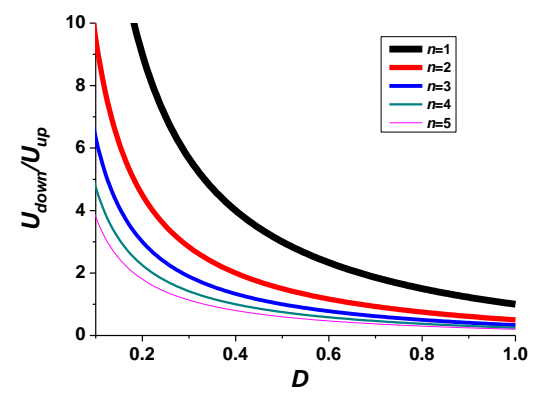

Fig.6 $U_{d o w n} / U_{u p}$ varied with turns ratio

\section{B. Three-Level Converter and Line Commutated Bridge}

With double asymmetric output voltages, a three-level converter can be realized by controlling $S_{1}$ and $S_{2}$ in a manner presented in Fig. 7. The bus voltage of $0, U_{u p}, U_{\text {down }}$, and $U_{u p}+U_{\text {down }}$ can be obtained from the three-level converter and used as the input to the line frequency commutated bridge.

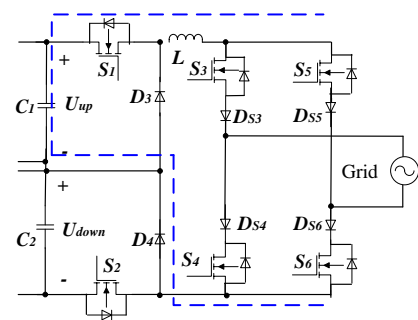

(a) $S_{1}$ on, $S_{2}$ off.

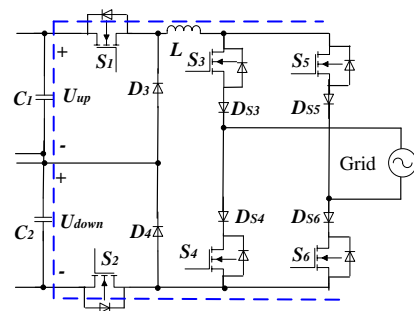

(c) $S_{1}$ on, $S_{2}$ on. (b) $S_{2}$ on, $S_{1}$ off.

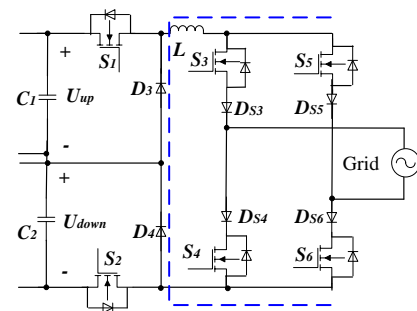

(d) $S_{I}$ off, $S_{2}$ off.

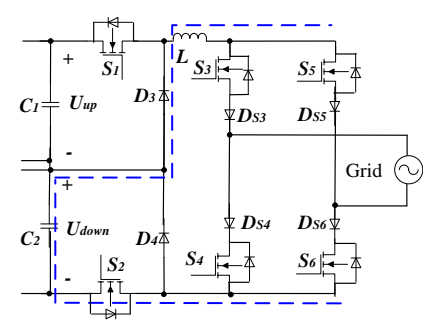

Fig. 7. Switching operation of the three-level dc-de converter.

As for the bridge operation, $S_{3}$ and $S_{6}$ are turned on and $S_{4}$ and $S_{5}$ are off when the instantaneous grid voltage is greater than zero, as presented in Fig. 8(a). When the grid voltage is below zero, $S_{4}$ and $S_{5}$ are on and $S_{3}$ and $S_{6}$ are off, as in Fig. 8(b). Obviously, this topology removes the dead time as appeared in conventional voltage-source inverters. Because of the switch capacitor structure of the three-level converter, the voltage stress of $S_{1}$ is clamped to $U_{u p}$ and that of $S_{2}$ to $U_{d o w n}$.

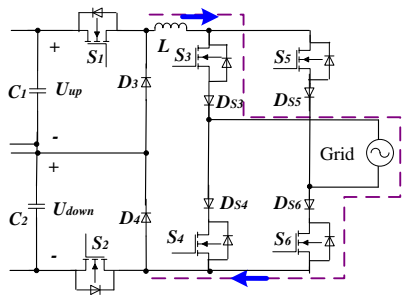

(a) $S_{3}$ and $S_{6}$ on, $S_{4}$ and $S_{5}$ off.

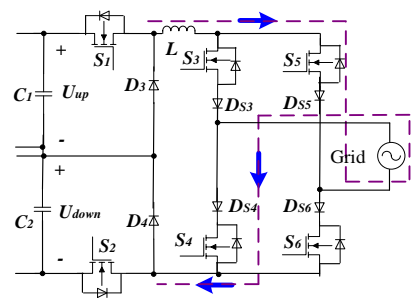

(b) $S_{4}$ and $S_{5}$ on, $S_{3}$ and $S_{6}$ off.
Fig. 8. Switching operation of the line frequency commutated bridge.

When connected with a filter inductor $(L)$, the voltage source becomes a current source, making the proposed system reliable and scalable. In essence, the multiple dc-dc current source modules can share the same line frequency commutated converter in a multi-string configuration. Consequently, the count of switching devices can be reduced.

\section{IMPROVED HYSTERESIS CONTROL}

Traditionally, the synchronized pulse-width modulation (SPWM) is widely used for cascade multilevel converters but not readily suited for asymmetric voltage input. In this work, 
the hysteresis control is thus considered and modified.

The switching frequency for the hysteresis control is,

$$
f_{h}=\frac{U_{d c}^{2}-u_{g r i d}^{2}}{4 H L U_{d c}}
$$

where $u_{\text {grid }}$ is the instantaneous line voltage, $H$ is the hysteresis bandwidth. However, neither the hysteresis band nor the filter inductance can be largely altered to allow a low switching frequency [34]. Therefore, the bus voltage is controlled according to the instantaneous grid voltage, which provides a fast dynamic response and simple current regulation for grid connection.

The block diagram and the switching schemes of the hysteresis control are depicted in detail in Figs. 9 and 10, respectively. In Fig. 9, the perturbation and observation is implemented in maximum power point control. The grid-connected current reference is calculated from outputs of the PV power and the bus voltage controller. The DC-link capacitor voltage is fed back and compared with the reference voltage $U_{r e}$. The bus voltage controller provides proportional control to compensate the grid-connected current amplitude. By adjusting the grid-connected current, the bus voltage can be controlled indirectly. The required current is calculated and updated in every line cycle in order to achieve fast response.

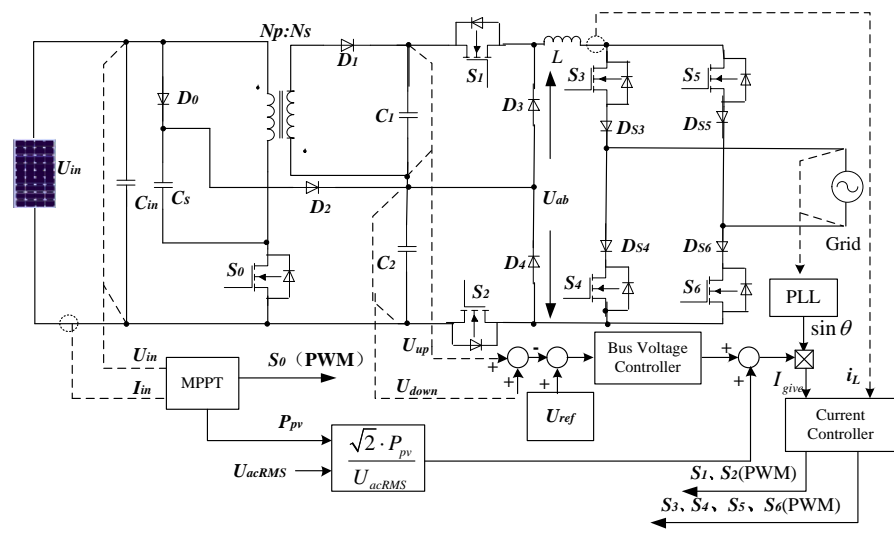

Fig. 9. Block diagram of the hysteresis control scheme.

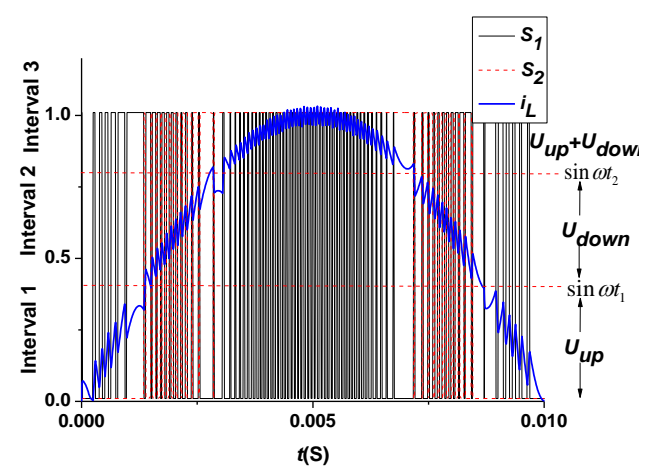

Fig. 10. $S_{1}$ and $S_{2}$ switching schemes and the voltage waveforms.

In Fig. 10, it can be seen that the bus voltage is divided into three stages: $0 \sim U_{\text {up }}, U_{\text {up }} \sim U_{\text {down }}, U_{\text {down }} \sim\left(U_{\text {up }}+U_{\text {down }}\right)$. The edge of each stage is determined by $t_{1}$ and $t_{2}$. During the interval $0 \sim \sin \omega t_{1}$ ( $\omega$ is the line angular frequency), $S_{l}$ is chopping and $S_{2}$ is turned off. The bus voltage changes between 0 and $U_{u p}$.

The maximum switching frequency of $S_{1}$ can be computed by:

$$
f_{1 \max }=\frac{U_{u p}}{2 H L}
$$

When the grid voltage increases to $U_{\text {grid }} \sin \omega t_{l}$ (where $U_{\text {grid }}$ is the amplitude of grid voltage), the switching event changes to the interval $\sin \omega t_{1} \sim \sin \omega t_{2}$. That is, $S_{2}$ is chopping and $S_{1}$ is turned off. The bus voltage varies between 0 and $U_{\text {down }}$. The maximum switching frequency of $S_{2}$ is given by:

$$
f_{2 \max }=\frac{U_{\text {down }}^{2}-\left(U_{\text {grid }} \sin \omega t_{1}\right)^{2}}{2 H L U_{\text {down }}}
$$

When the grid voltage reaches $U_{\text {grid }} \sin \omega t_{2}, S_{1}$ is chopping and $S_{2}$ stays on for the interval $\sin w t_{2} \sim 1$. The bus voltage changes between $U_{d o w n}$ and $U_{d c}$. The switching cycle of $S_{I}$ can be calculated by:

$$
T_{3}=\frac{2 H L\left(U_{d c}-U_{\text {down }}\right)}{\left(U_{d c}-U_{\text {grid }}\right)\left(U_{\text {grid }}-U_{\text {down }}\right)}
$$

The switching frequency as a functions of the graded voltage level for the three-stage hysteresis control scheme is summarized in Table I. It can been observed that the voltage difference at each stage in the three-stage hysteresis control is still high, making it difficult to further decrease the switching frequency variations. Thereby, a five-stage hysteresis control is proposed with a detailed switching scheme also given in Table I. For this five-stage hysteresis control, the output voltages can be obtained between $\quad 0 \sim U_{u p}, \quad 0 \sim U_{\text {down }}, \quad U_{u p} \sim U_{\text {down }}$, 
$U_{\text {down }} \sim\left(U_{u p}+U_{\text {down }}\right)$, and $U_{u p} \sim\left(U_{u p}+U_{\text {down }}\right)$.

Fig. 11 presents a comparison of the switching frequency between the traditional hysteresis control with full bridge topology and the five-stage hysteresis control scheme with the proposed topology under the same condition over one quarter of the cycle. Clearly, the five-stage control scheme has lower switching frequencies $(5-35 \mathrm{kHz})$ than the three-stage hysteresis control $(30-80 \mathrm{kHz})$. This implies a relaxed switching requirement, less EMI and THD, and lower switching losses.

TABLE I

Comparison of the Three- And Five-Stage Hysteresis Control

\begin{tabular}{|c|c|c|c|c|}
\hline Control & Stage & $S_{1}$ & $S_{2}$ & Switching frequency \\
\hline \multirow{5}{*}{ 3-stage } & 1 & PWM & off & $\frac{U_{u p}^{2}-U_{g r i d}^{2}}{4 H L U_{u p}}$ \\
\hline & \multirow{2}{*}{2} & \multirow[b]{2}{*}{ off } & \multirow[b]{2}{*}{ PWM } & $U_{\text {down }}^{2}-U_{\text {grid }}^{2}$ \\
\hline & & & & $4 H L U_{\text {down }}$ \\
\hline & \multirow{2}{*}{3} & \multirow{2}{*}{ PWM } & \multirow{2}{*}{ on } & $\left(U_{d c}-U_{\text {grid }}\right)\left(U_{\text {grid }}-U_{d o w n}\right)$ \\
\hline & & & & $2 H L U_{u p}$ \\
\hline \multirow{10}{*}{ 5-stage } & \multirow{2}{*}{1} & \multirow{2}{*}{ PWM } & \multirow{2}{*}{ off } & $U_{u p}^{2}-U_{g r i d}^{2}$ \\
\hline & & & & $4 H L U_{u p}$ \\
\hline & \multirow{2}{*}{2} & \multirow{2}{*}{ off } & \multirow{2}{*}{ PWM } & $U_{\text {down }}^{2}-U_{\text {grid }}^{2}$ \\
\hline & & & & $4 H L U_{\text {down }}$ \\
\hline & \multirow{2}{*}{3} & \multirow{2}{*}{ PWM } & \multirow{2}{*}{ PWM } & $\left(U_{\text {down }}-U_{\text {grid }}\right)\left(U_{\text {grid }}-U_{u p}\right)$ \\
\hline & & & & $2 H L\left(U_{\text {down }}-U_{u p}\right)$ \\
\hline & \multirow{2}{*}{4} & \multirow{2}{*}{ on } & \multirow{2}{*}{ PWM } & $\left(U_{d c}-U_{\text {grid }}\right)\left(U_{\text {grid }}-U_{u p}\right)$ \\
\hline & & & & $2 H L U_{d o w n}$ \\
\hline & \multirow{2}{*}{5} & \multirow{2}{*}{ PWM } & \multirow{2}{*}{ on } & $\left(U_{d c}-U_{\text {grid }}\right)\left(U_{\text {grid }}-U_{d o w n}\right)$ \\
\hline & & & & $2 H L U_{u p}$ \\
\hline
\end{tabular}

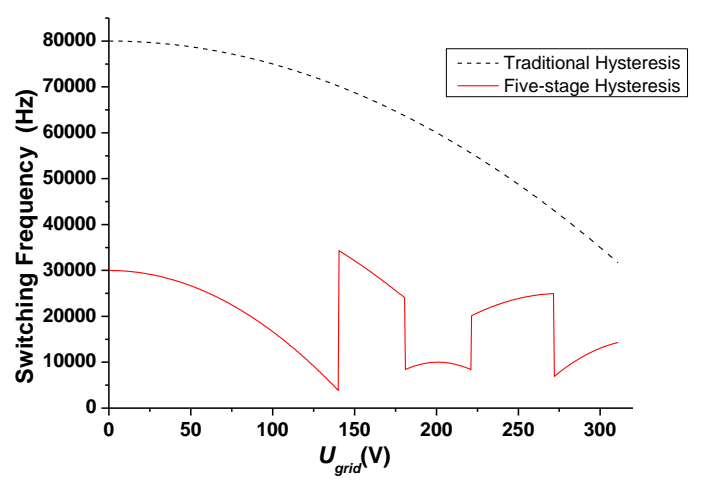

Fig. 11. The switching frequency for the hysteresis control.

\section{Simulation AND EXPERIMENTAL RESUlTS}

The proposed inverter topology and control scheme are simulated in Matlab/Simulink environment and implemented in a 600W prototype (see Fig. 12a). The PV array (Fig. 12b) includes six panels of the polycrystalline PV module controlled with a Texas Instruments TMS320F2812 controller. The specifications of the PV module and the inverter are tabulated in Table II. The coupled inductor is constructed from the Ferrites EE 40 magnetic material and its primary and secondary turns are 20 and 60 , respectively.

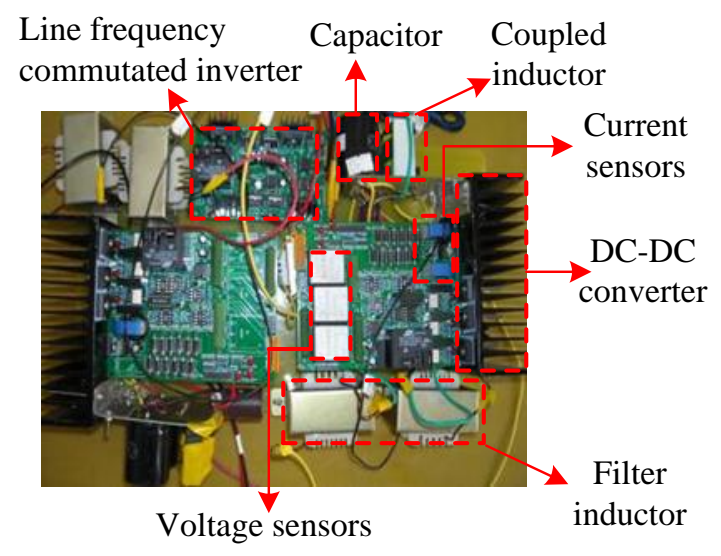

(a) The prototype inverter.

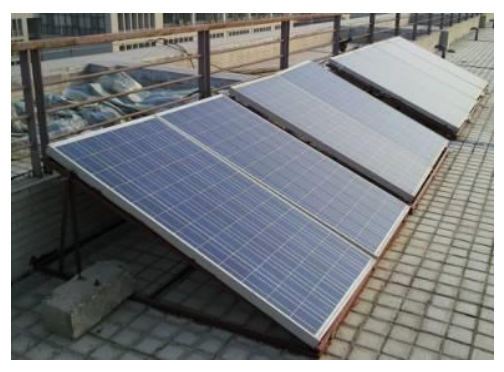

(b) The PV array.

Fig. 12. Experimental setup of the proposed inverter and the PV array.

TABLE II

SPECIFICATIONS OF THE PV MODULE AND THE INVERTER

\begin{tabular}{|c|c|c|}
\hline Item & Parameter & Value \\
\hline \multirow{7}{*}{ PV } & Open voltage (V) & 44.8 \\
\hline & Short current (A) & 5.29 \\
\hline & MPP current (A) & 5 \\
\hline & MPP voltage (V) & 36 \\
\hline & Current temperature coefficient $\left(\% /{ }^{\circ} \mathrm{C}\right)$ & 0.037 \\
\hline & Voltage temperature coefficient $\left(\% /{ }^{\circ} \mathrm{C}\right)$ & -0.34 \\
\hline & Power temperature coefficient $\left(\% /{ }^{\circ} \mathrm{C}\right)$ & -0.48 \\
\hline \multirow{12}{*}{ Converter } & Output power $(\mathrm{W})$ & 600 \\
\hline & Input voltage $(\mathrm{V})$ & $50-80$ \\
\hline & Bus voltage $(\mathrm{V})$ & 380 \\
\hline & Sampling frequency $(\mathrm{kHz})$ & 20 \\
\hline & $\mathrm{C}_{\mathrm{S}}(\mu \mathrm{F})$ & 100 \\
\hline & $\mathrm{C}_{1}$ and $\mathrm{C}_{2}(\mu \mathrm{F})$ & 450 \\
\hline & $\mathrm{L}(\mathrm{mH})$ & 2.5 \\
\hline & Turns ratio of $L_{\mathrm{C}}$ & 20:60 \\
\hline & Grid voltage/frequency & $220 \mathrm{~V} / 50 \mathrm{~Hz}$ \\
\hline & $D_{0}, D_{1}, D_{2}, D_{3}, D_{4}$ & APT30DQ60B \\
\hline & $S_{1} S_{2}, S_{3}, S_{4}, S_{5}, S_{6}$ & IRFP460 \\
\hline & $D_{s 3}, D_{s 4}, D_{s 5}, D_{s 6}$ & MUR1560 \\
\hline
\end{tabular}

Matlab simulation results for the three-stage and five-stage hysteresis control schemes are demonstrated in Fig. 13 for comparison. Clearly, the five-stage hysteresis control scheme 
produces a much more balanced switching frequency distribution and output current distribution, and two (?) more voltage levels than the three-stage control scheme, leading to improved thermal and EMI performance of the inverter.

Fig. 14 shows the experimental results from the dc-dc converter with $49.3 \mathrm{~V}$ input, $220 \mathrm{~V}$ output and 0.4 duty ratio. The measured and calculated voltage gains are 4.46 and 4.66 , respectively, which agree well with one another. Compared to the topologies presented in [8] and [13], the proposed topology in this paper can achieve a $38 \%$ and $23 \%$ higher voltage gain, respectively.
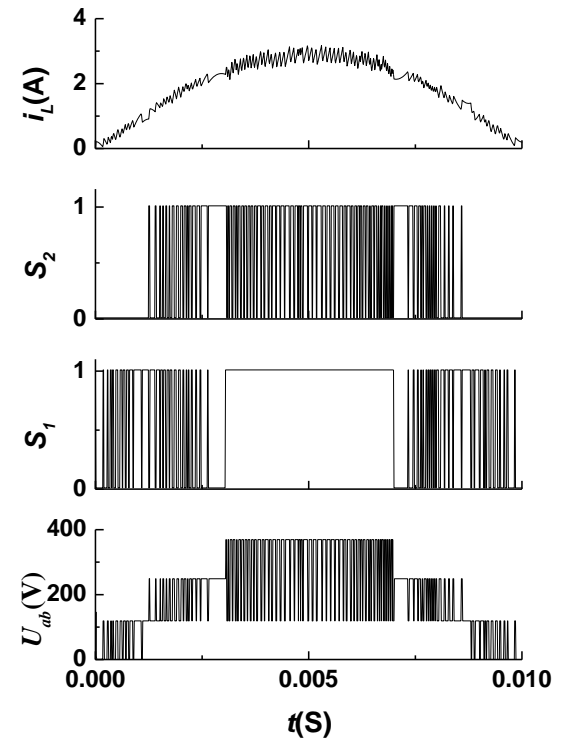

(a) Three-stage hysteresis control.

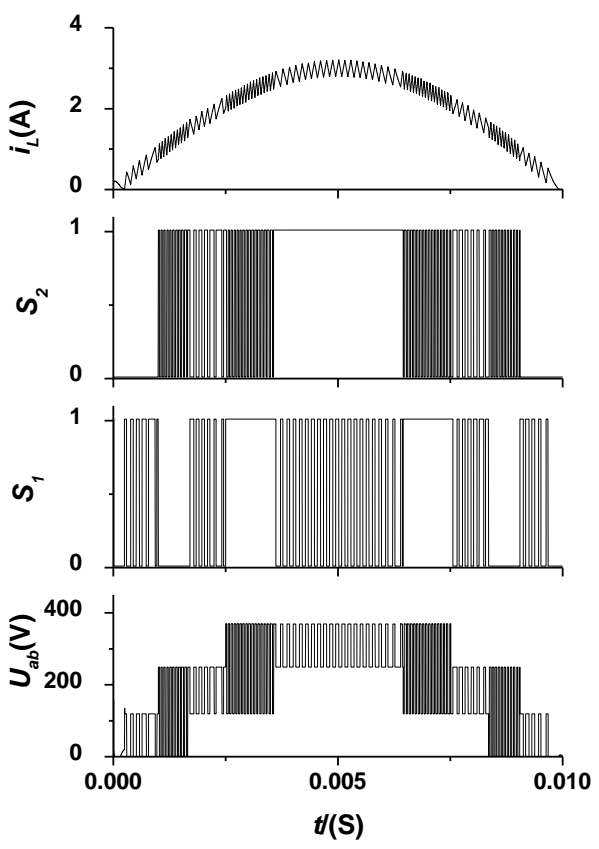

(b) Five-stage hysteresis control.

Fig. 13. Simulation results for the two hysteresis control schemes.

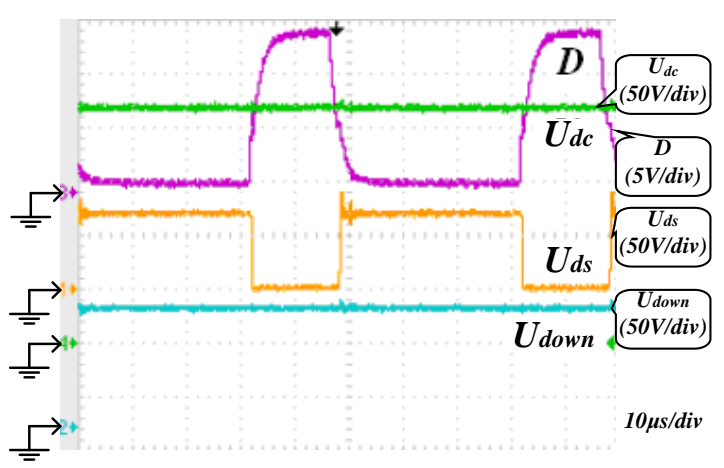

Fig. 14. Measured waveforms from the dc-dc converter.

Fig. 15(b) presents the experiment results of multi-stage hysteresis control. Fig.15 (b) illustrates the experimental results of traditional hysteresis control. The switching frequency is high and low grid-connecting quality (?). Fig. 15 (c) present the experimental results for the three-stage hysteresis control. It is observed that the output current is approximately sinusoidal with a current ripple of $0.24 \mathrm{~A}$. Fig. 15(d) shows the experimental results for five-stage hysteresis control, which has a lower current ripple $(0.15 \mathrm{~A})$ and improved switching frequency distribution. The voltage $U_{a b}$ in Fig. 15(e) presents four distinct voltage levels and, because of this, the current is highly sinusoidal and synchronized well with $U_{\text {grid }}$. Fig. 15(f) shows the waveforms of the bus voltage, line current and lower-output voltage with $75 \mathrm{~V}$ input voltage and $385 \mathrm{~V}$ bus voltage. In this case, the voltage gain is 5.13 , which proves the step-up capability of the proposed converter. The efficiency of the proposed converter at rated conditions is $92.4 \%$ which is higher than a similar five-level converter reported in [25]. In addition, this can be improved further if thyristors are used in the line frequency commutated bridge.

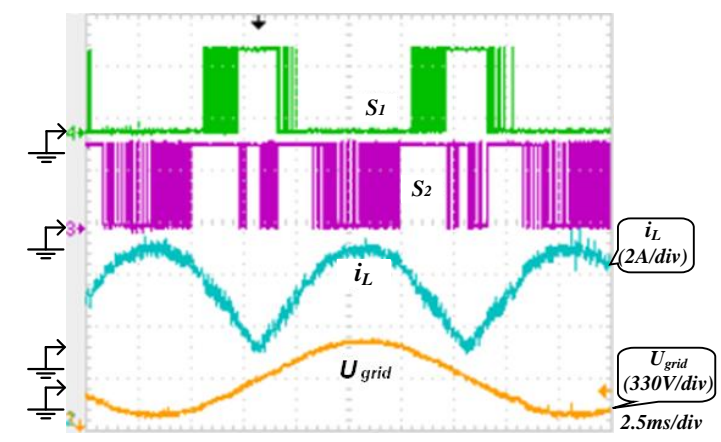

(a) Experimental results of $S_{1}, S_{2}, I_{\text {grid }}$ and $U_{\text {grid }}$ 


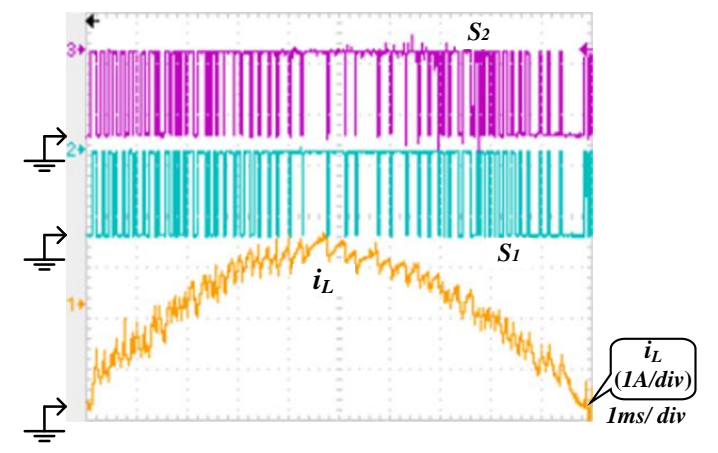

(b) Experimental results of traditional hysteresis control.

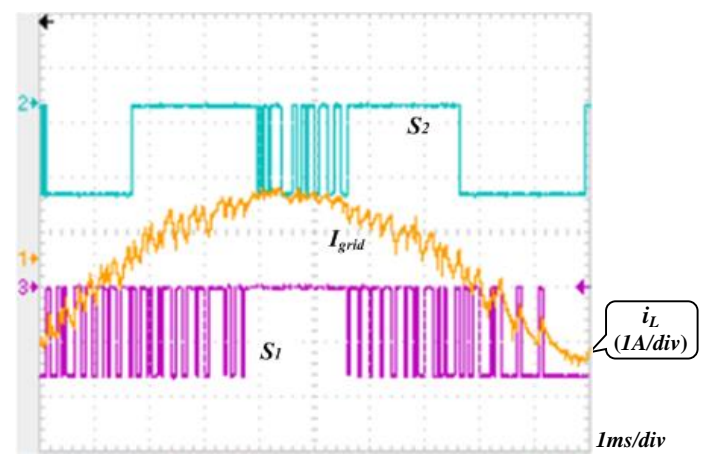

(c) Experimental results of the three-stage hysteresis control.

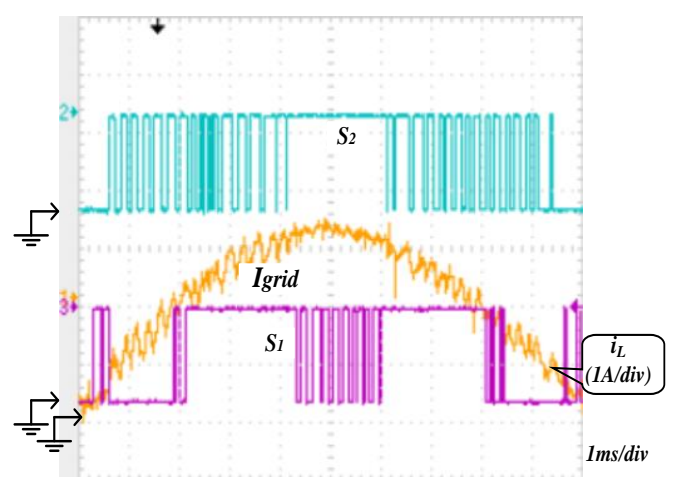

(d) Experimental results of the five-stage hysteresis control.

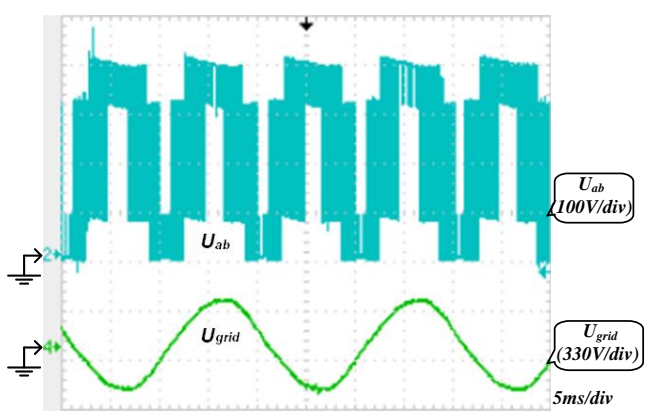

(e) Experimental results for 5-stage control. (need text?)

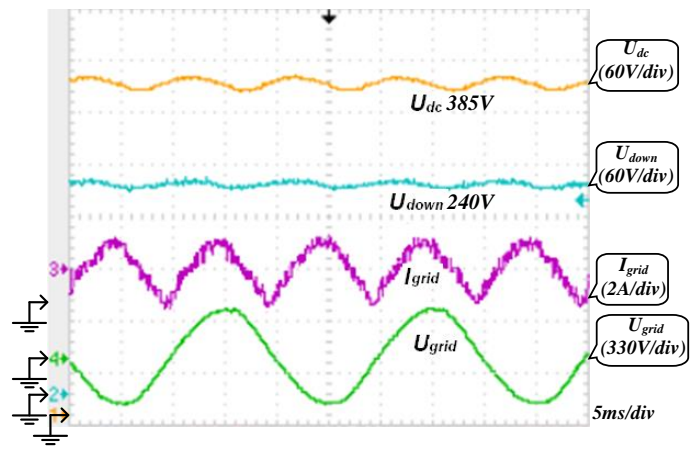

(f) Experimental results of the bus voltage, line current and voltage

Fig. 15. Measured waveforms from the hysteresis control schemes.

Furthermore, a spectrum analysis using the fast Fourier transform (FFT) is carried out whose results are presented in Fig. 16 for comparison. It can be seen that the THD for the first 50 harmonic components in the output current is $6.84 \%$ for the traditional hysteresis control and $3.63 \%$ for the five-stage hysteresis control schemes. Again, it is confirmed that the developed technology reduces the THD and improves the switching frequency distribution of the converter.

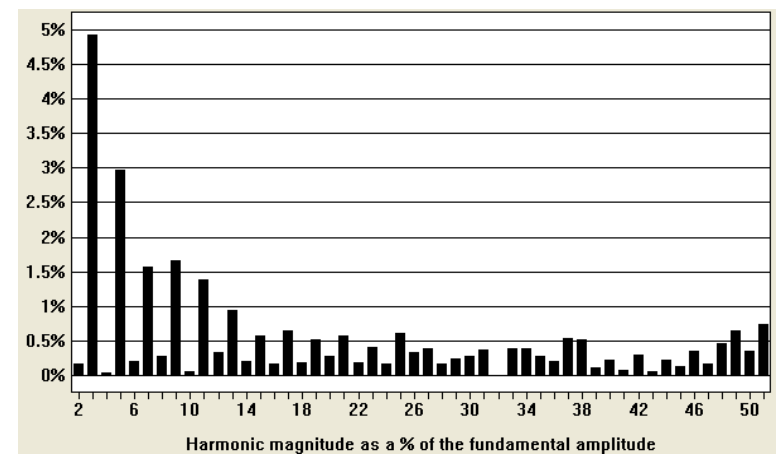

(a) Harmonic analysis of the traditional hysteresis control.

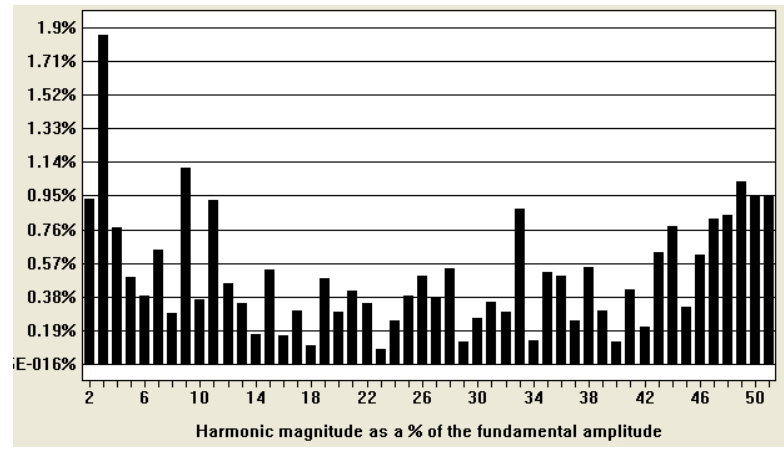

(b) Harmonic analysis of the five-stage hysteresis control.

Fig. 16. Harmonic analysis of experimental results. 


\section{CONCLUSIONS}

This paper has presented a new inverter topology with improved control scheme for grid-connected PV systems. The high step-up dc-dc converter with one switch is employed to provide a high voltage gain. A range of voltage levels can be attained from the inverter with the proposed multi-stage hysteresis control scheme and the effectiveness of the inverter is validated by experiential tests on a $600 \mathrm{~W}$ prototype converter.

The proposed converter topology with multi-stage hysteresis control has following advantages:

(1) The asymmetrical high voltage output is realized by using one switch in the high step-up DC-DC converter;

(2) The multilevel output is achieved by controlling two active switches;

(3) The dead time as in other voltage-source inverters is eliminated.

(4) Because of the multi-stage hysteresis control, the required switching frequency is significantly decreased and the output current quality is thus improved.

(5) The developed photovoltaic systems are flexible, scalable and cost-effective, suited particularly for developing countries with low-voltage distributed-generation power networks.

\section{REFERENCES}

[1] H. Yi, F. Z. Peng, W. Jin, D. W. Yoo, "Survey of the power conditioning system for PV power generation," the 37th IEEE Power Electronics Specialists Conference, pp. 1-6, 2006.

[2] Q. Li and P. Wolfs, "A review of the single phase photovoltaic module integrated converter topologies with three different dc link configurations," IEEE Trans. Power Electron., vol. 23, no. 3, pp. 1320-1333, May. 2008.

[3] J. M. Kwon, B. H. Kwon, and K. H. Nam, "Grid-connected photovoltaic multistring PCS with PV current variation reduction control," IEEE Trans. Industrial Electronics, vol. 56, no. 11, pp. 4381-4388, Nov. 2009.

[4] H. Patel and V. Agarwal, "Maximum power point tracking scheme for PV systems operating under partially shaded conditions," IEEE Trans. Industrial Electronics, vol. 55, no. 4, pp. 1689-1698, Apr. 2008.

[5] D. Nguyen, B. Lehman, "An adaptive solar photovoltaic array using model-based reconfiguration algorithm," IEEE Trans. Industrial Electronics, vol. 55, no.7, pp. 2644-2654, July. 2008.

[6] G. Velasco-Quesada, F. Guinjoan-Gispert, R. Piqué-López, M. Román-Lumbreras and A. Conesa-Roca, "Electrical PV array reconfiguration strategy for energy extraction improvement in grid-connected PV systems," IEEE Trans. Industrial Electronics, vol. 56, no. 11, pp. 4319-4331, Nov. 2009.

[7] B. N. Alajmi, K. H. Ahmed, S. J. Finney, B. W. Williams, "A maximum power point tracking technique for partially shaded photovoltaic systems in microgrids," IEEE Trans. Industrial Electronics, vol. 60, no. 4, pp.1596-1606, April 2013.

[8] Q. Zhao and F. C. Lee, "High-efficiency, high step-up DC-DC converters," IEEE Trans. Power Electron., vol. 18, no. 1, pp. 65-73, Jan. 2003.
[9] R. J. Wai and R. Y. Duan, "High step-up converter with coupled-inductor," IEEE Trans. Power Electron., vol. 20, no. 5, pp. 1025-1035, Sep. 2005.

[10] S. B. Kjaer, J. K. Pedersen and R. Y. Duan, "A review of single-phase grid connected inverters for photovoltaic modules," IEEE Trans. Ind Appl., vol. 41, no. 5, pp. 1292-1369, Sept. /Oct. 2005.

[11] R. J. Wai, C. Y. Lin, R. Y. Duan, Y. R. Chang, "High-efficiency dc-dc converter with high voltage gain and reduced switch stress," IEEE Trans. Industrial Electronics, vol. 54, no. 1, pp.354-364, Feb. 2007.

[12] M. Prudente, L. L. Pfitscher, G. Emmendoerfer, E. F. Romaneli, and R. Gules, "Voltage multiplier cells applied to non-isolated dc-dc converters," IEEE Trans. Power Electron., vol. 23, no. 2, pp. 871-887, Mar. 2008.

[13] E. H. Ismail, M. A. Al-Saffar, A. J. Sabzali and A. A. Fardoun, "A family of single-switch PWM converters with high step-up conversion ratio," IEEE Trans. Circuits and Systems, vol. 55, no. 4, pp. 1159-1171, May 2008.

[14] W. Li and X. He, "A family of interleaved dc-dc converters deduced from a basic cell with winding-cross-coupled inductors (wccis) for high step-up or step-down conversions," IEEE Trans. Power Electron., vol. 23, no. 4, pp. 1791-1801, July 2008.

[15] B. Yang, W. Li, Y. Zhao and X. He, "Design and analysis of a grid-connected photovoltaic power system," IEEE Trans. Power Electron., vol. 25, no. 4, pp. 992-1000, Apr. 2010.

[16] B. Yuan, X. Yang, X. Zeng, J. Duan, J. Zhai, D. Li, “Analysis and design of a high step-up current-fed multiresonant dc-dc converter with low circulating energy and zero-current switching for all active switches," IEEE Trans. Industrial Electronics, vol. 59, no. 2, pp. 964-978, Feb. 2012.

[17] Z. Zhao. M. Xu, Q. Chen, J. S. Lai, Y. Cho, "Derivation, analysis, and implementation of a boost-buck converter-based high-efficiency PV inverter," IEEE Trans. Power Electron., vol. 27, no. 3, pp. 1304-1313, Mar. 2012.

[18] S. M. Chen, T. J. Liang, L. S. Yang and J. F. Chen, "A safety enhanced, high step-up dc-dc converter for ac photovoltaic module application," IEEE Trans. Power Electron., vol. 27, no. 4, pp. 1809-1817, Apr. 2012.

[19] P. G. Barbosa, H. A. C. Braga, M. C. B. Rodrigues, E. C. Teixeira, "Boost current multilevel inverter and its application on single-phase grid-connected photovoltaic systems," IEEE Trans. Power Electron., vol. 21, no. 4, pp.1116-1124, July 2006.

[20] S. Daher, J. Sccchmid, and F. L. M. Antunes, "Multilevel inverter topologies for stand-alone PV systems," IEEE Trans. Industrial Electronics, vol. 55, no. 7, pp. 2703-2712, July 2008.

[21] S. B. Monge, J. Rocabert, P. Rodríguez, S. Alepuz and J. Bordonau, "Multilevel diode-clamped converter for photovoltaic generators with independent voltage control of each solar array," IEEE Trans. Power Electron., vol. 55, no. 7, pp. 2713-2723, July 2008.

[22] R. González, E. Gubía, J. López and L. Marroyo, "Transformerless single-phase multilevel-based photovoltaic inverter," IEEE Trans. Power Electron., vol. 55, no. 7, pp. 2694-2702, July 2008.

[23] J. Selvaraj, N. A. Rahim, "Multilevel inverter for grid-connected pv system employing digital pi controller," IEEE Trans. Industrial Electronics, vol. 56, no. 1, pp. 149-158, Jan. 2009.

[24] E. Villanueva, P. Correa, J. Rodríguez and M. Pacas, "Control of a single-phase cascaded H-bridge multilevel inverter for grid-connected photovoltaic system," IEEE Trans. Power Electron., vol. 56, no. 11, pp. 4399-4406, Nov. 2009.

[25] N. A. Rahim, J. Selvaraj, "Multistring five-level inverter with novel PWM control scheme for PV application," IEEE Trans. Industrial Electronics, vol. 57, no. 6, pp. 2111-2123, June 2010.

[26] J. Chavarria, D. Biel, F. Guinjoan, C. Meza, J. J. Negroni, "Energy-balance control of PV cascaded multilevel grid-connected inverters under level-shifted and phase-shifted PWMs," IEEE Trans. Industrial Electronics, vol. 60, no. 1, pp. 98-111, Jan. 2013.

[27] S. Buso, S. Fasolo, L. Malesani, P. Mattavelli, "A dead-beat adaptive hysteresis current control," IEEE Trans. Ind Appl., vol. 36, no. 4, pp. 1174-1180, July/Aug. 2000.

[28] X. Mao, R. Ayyanar, H. K. Krishnamurthy, "Optimal variable switching frequency scheme for reducing switching loss in single-phase inverters 
based on time-domain ripple analysis," IEEE Trans. Power Electron., vol. 24, no. 4, pp. 991-1001, Apr. 2009.

[29] O. Lopez-Lapena, M. T. Penella, M. Gasulla, "A closed-loop maximum power point tracker for subwatt photovoltaic panels," IEEE Trans. Industrial Electronics, vol. 59, no. 3, pp. 1588-1596, March 2012.

[30] C. N. Ho, V. S. P. Cheung, H. S. Chung, "Constant-frequency hysteresis current control of grid-connected VSI without bandwidth control," IEEE Trans. Power Electron., vol. 24, no. 11, pp. 2484-2495, Nov. 2009.

[31] W. Stefanutti, P. Mattavelli, "Fully digital hysteresis modulation with switching-time prediction," IEEE Trans. Ind Appl., vol. 42, no. 3, pp. 763-769, May/June 2006.

[32] K. A. Corzine, "A hysteresis current-regulated control for multi-level drives," IEEE Trans. Energy Conversion, vol. 15, no. 2, pp. 169-175, Jun. 2000.

[33] M. Marchesoni, "High-Performance current control techniques for applications to multilevel high-power voltage source inverters," IEEE Trans. Power Electron., vol. 7, no. 1, pp. 189-204, Jan. 1992.

[34] O. Ichinokura, T. Kagami, J. Toshimasa, M. Maeda, Y. Wakiya, "High speed variable-inductor controlled with DC-DC converter," IEEE Trans. Magnetics, vol. 31, no. 6, pp.4247-4249, Nov. 1995. 